\title{
Air Quality in Sport Facilities
}

\begin{abstract}
In new buildings, there are increasingly stringent requirements for ventilation, both in terms of energy consumption and air quality. Major sports facilities such as football halls, multifunctional halls and ice halls have fallen under the radar with lack of requirements concerning air quality, although materials and processes often emit more than in normal commercial buildings and houses. The aim of this project was to characterize the air quality in sport facilities. To identify the challenges concerning sport facilities, it was decided to look at ice halls. Ice halls have special demands concerning heating and cooling and therefore, dimensioning of such ventilation systems can be challenging in terms of moisture and temperature requirements. Firstly, a literature study was conducted on relevant literature concerning air quality in ice halls. The majority of previous research on indoor air quality contained research about poor air quality in ice halls because of the combustion engine in the resurfacers. The work by several previous researches confirmed that many ice halls do not have enough fresh air supply. Also, a literature study was conducted concerning bad air quality affections on productivity, health and cognitive functions. In addition to the literature study, field measurements were conducted at Dalgård ice hall to study the air quality in practice. Dalgård ice hall has no active fresh air supply or ventilation system for the ice rink. The air quality on the ice rink was measured to characterize the air quality in the breathing zone of the players. Typical air quality parameters such as particulate matter, temperature, relative humidity and $\mathrm{CO}_{2}$ concentration were measured. The $\mathrm{PM}_{10}$ values were by the ice rink stable at $80 \mu \mathrm{g} / \mathrm{m}^{3}$, and the $\mathrm{CO}_{2}$ concentration increased from $870 \mathrm{ppm}$ to almost $1400 \mathrm{ppm}$ in just under three hours with stabile high activity. Both values were above the recommended values from The World Health Organization (WHO) and Norwegian Institute of Public Health, on $50 \mu \mathrm{g} / \mathrm{m}^{3}$ and $1000 \mathrm{ppm}$ respectively. The conclusion was that there could be more stringent air quality requirements in such sport facilities. Young people spend a lot of time in these halls with a high pulmonary ventilation. For workers and visitors exposed to the air in the ice rink on a regular basis it is important to ensure proper air quality.
\end{abstract}

\section{Introduction}

Today, humans spend around $90 \%$ of their time indoor. These places can be residential buildings, offices, schools, shopping arenas or sport facilities. The air quality in these buildings eventually gained much attention in the 1970s when scientists connected bad air quality with decreased productivity, illness and respiratory health problems [1]. Therefore, it has gradually become more focus on technical installations to improve the air quality and indoor environment. [1-2]

Sport facilities, and especially ice halls have challenges related to energy efficiency and good indoor climate. While the temperature must be low enough to maintain a good ice quality, the spectators demands a certain thermal comfort to ensure a satisfying indoor climate. To combine a good ventilation and energy use is therefore a demanding issue. At the same time, poor ventilation is adequate to poor air quality. International ice hockey federation (IIHF) has a publication called "IIHF ice rink guide" that gives extensive information about building and maintaining the ice rink. This guideline suggests mechanical ventilation to control the indoor air quality and thermal conditions inside the ice rink. This is not a demand, just a guideline. Dalgård ice hall has no fresh air supply and ventilation and is therefore likely to have challenges with the indoor climate and air quality.

\subsection{Ice hockey halls}

An ice hall is primary used for hockey during the late autumn, winter and early spring. Also, it is sometimes used for normal and figure skating. Newer ice halls can extend the period for skaters to play hockey. These halls are developed and built using IIHF's "ice rink guide" as a guideline. This guideline gives information about construction, operation and economics. [3]

To ensure a functioning ice hall, the guideline gives suggestions in several features:

- The building envelope should be insulated

- The ventilation should have fresh air supply and be mechanical only

- The heating system should be efficient with a good heat recovery unit

- Air de-humidification for maintaining the ice and reduce fog

- Proper lighting to ensure a good actinic environment 


\subsection{Regulations and guidelines}

Indoor air quality is a measure of how clean the air is. The air quality varies according to the amount of harmful pollutant in the air. Regulations and standards enforce how many different substances are accepted, both average daily and annual quantities.

Pollutions is emissions from humans, processes, materials and outdoor pollution. Humans contaminate in the form of water vapor, odour and dust. These three contaminants are not harmful but can be uncomfortable in big amounts. Harmful substances, however, can be created from chemicals and processes.

The most traditional way to indicate the air quality is to measure $\mathrm{CO}_{2}$ in the air. $\mathrm{CO}_{2}$ is measured in part per million (ppm). The $\mathrm{CO}_{2}$ concentration in outdoor air varies during the year, with an average of 400 ppm in Norway. According to NS-15251 it is important to look at the difference between the indoor and outdoor $\mathrm{CO}_{2}$ concentrations to determine how well the indoor air quality is. Four categories are made to describe the air quality requirements. [4]

Table 1: Recommended $\mathrm{CO}_{2}$ concentration in categories NS-EN 15251 [4]

\begin{tabular}{ll}
\hline Category & ppm: \\
\hline 1 & 350 \\
2 & 500 \\
3 & 800 \\
4 & $>800$ \\
\hline
\end{tabular}

Normal buildings such as buildings for public and spectators should aim to reach category 2. In addition to the categories of $\mathrm{CO}_{2}$ concentration, the Norwegian Institute of Public Health gives a recommended maximum value of $1000 \mathrm{ppm} \mathrm{CO}_{2}$. [1]

Particulate matter (PM) is one type of pollution, also called aerosols. Aerosols is airborne particles that floats in the air. The occurrence of PM in indoor air depends on the ventilation conditions of the building and the number of particles in the ambient air, as well as formation of particles indoors. Particulate matter is categorized by their diameter size. The main categories are $\mathrm{PM}_{10}, \mathrm{PM}_{2,5}$ and $\mathrm{PM}_{0,1}$. Limit values can be seen in Table 2 .

Table 2: Limit values for particle matter concentration given by two institutions. $\left[\mu \mathrm{g} / \mathrm{m}^{3}\right][1,5]$

\begin{tabular}{lll}
\hline & $\mathrm{PM}_{2.5}$ & $\mathrm{PM}_{10}$ \\
\hline $\begin{array}{l}\text { Annual mean values } \\
\text { World health Organization }\end{array}$ & 10 & 20 \\
$\begin{array}{l}\text { Norwegian Institute of Public Health } \\
\text { 24-hour mean values }\end{array}$ & 8 & 20 \\
$\begin{array}{l}\text { World health Organization } \\
\text { Norwegian Institute of Public Health }\end{array}$ & 25 & 50 \\
\hline
\end{tabular}

\section{Literature study}

By using PubMed, NTNU Oria, ScienceDirect and google (scholar version) literature studies were revieved. The reason for the literature study was to make an overview and understanding of the challenges associated with air quality and indoor environment in sports facilities, and especially ice halls. Studies on how PM level and $\mathrm{CO}_{2}$ concentration are in ice halls and sports facilities in general were reviewed. This was to map what can be done to improve the air quality.

\subsection{Indoor environment in ice halls}

The air quality is what affects the indoor climate the most. Even though the air quality is bad, it can be perceived as good. It is a big difference in perceived and actual air quality. One study has shown that the air quality is perceived better when the temperature is cold, compared to when it is warm. Players and spectators could perceive the air quality better than it is because of the cold temperature in ice halls. [6]

Several studies have conducted that the air quality in ice halls can be less satisfying than wanted. And that several parameters such as $\mathrm{NO}_{2}, \mathrm{PM}$ and $\mathrm{CO}$ exceed the recommended values from WHO. It is likely that this happened especially because of the combustion engines used in the resurfacers. [7-10]

The PM concentration in the ice rinks is according to K. W. Rundell's study, high compared to outdoor concentration. The study conclude that PM values on the ice rink leads to poor air quality, and may be causal to the unique and high prevalence of airway dysfunction in ice arena athletes. [7]

\subsection{Health effects}

Athletes such as hockey players have very high intensity while they are on the rink. They have high pulse, make many decisions in short time and are fully concentrated to play at their best. It is crucial that they are healthy and that the respiratory functions are optimal.

Regarding the correlation between particulate matter and health effects, several studies conclude that it is a context between coarse particles, like $\mathrm{PM}_{10}$, and adverse health effects such as respiratory sickness and asthma. [11-14]

Seppänen reviewed literature on associations of ventilation rates and $\mathrm{CO}_{2}$ concentrations with health and other human outcomes. His review shows that ventilation rates below $10 \mathrm{l} / \mathrm{s}$ in all buildings were associated with significant worsening in one or more health outcomes. And low ventilation rates are associated with high $\mathrm{CO}_{2}$ levels when the occupancy is high. [15]

Surveys about productivity and $\mathrm{CO}_{2}$ concentration can be related to ice hockey and other sports, as the decisions during a match and training 
are many. A survey conducted in 2012 shows the relationship between reduction in cognitive functions and increasing $\mathrm{CO}_{2}$ concentration. 24 humans participated in this survey. They went through a working week with 8 hour a day in 6 days. Different days had different $\mathrm{CO}_{2}$ concentration in the office space. When there was $1400 \mathrm{ppm}$ concentration, the cognitive function was reduced with $50 \%$, compared to when there were $550 \mathrm{ppm}$ in the offices. The same type of survey was conducted by Satish et al., looking at decision-making performance in 600ppm, 1000ppm and 2500ppm. 22 participants went through a decision-making test under each condition. This study concluded: Relative to $600 \mathrm{ppm}$, at $1000 \mathrm{ppm}$ moderate and statistically significant decrements occurred in six of nine scales of decision-making performance. [36-37]

\section{Method for measurements}

\subsection{Dalgård ice hall}

Dalgård ice hall was built in 1989 in Byåsen. The hall is a part of a major sports arena with several football pitches and running track for athletics. The Ice Hall is open for hockey and other ice activities from September to March every year.

The air distribution in Dalgård ice hall is only recirculated air. Two exhaust ducts with fans are installed in the main hall to remove old air. These are disconnected because of too low dimension in the fuses. Therefore, there is no controlled fresh air in, and no exhaust air out. The only air change is because of infiltration and open doors. A recirculation system is installed to ensure satisfying temperature on the tribune. The air is supplied to the recirculation unit from the east side and supplied over the tribune on the west side. It is installed two de-humidifiers to ensure low humidity. These installations also keep the air moving in the hall, and thus gives a better air quality because the air does not remain in a place for a long time. The de-humidifiers are running if the air humidity exceeds a certain level.

The ice hall uses electric resurfacer to prepare the ice. The measurements were mainly conducted by the ice rink, as close as possible to the breathing zone for the players.

\subsection{Method}

For the measurements it is used three instruments for the different parameters. The field study included:

- Measure the particle matter concentration in the air in the hall, sharpening room, tribune and wardrobe during a day with different activity levels and occupancy.

- Measure the $\mathrm{CO}_{2}$ concentration in the occupied zones on the rink, and in the wardrobe with different amount of people.

- Temperature and humidity measurements in different zones in the hall and in one wardrobe.

\subsection{Instruments}

\subsubsection{Kimo AQ 200}

AQ 200 is a device which can measure a lot of units, depending on which probe is connected to the device. In this field study, a $\mathrm{CO}_{2} /$ Temperature probe was used. This device runs on batteries, or directly connected to power. The probe har a twisted wire connected to the device, which make it possible to keep the device inside a bag, while the probe is outside taking the measurements. [18]

\subsubsection{Alphasense OPC-N2, optical particle counter}

For the particle matter measurements, OPC-N2 were used. This device measures both $\mathrm{PM}_{1}, \mathrm{PM}_{2,5}$ and $\mathrm{PM}_{10}$ according to the method in EN481. The method OPC-N2 uses is that the light scattered by individual particles in a sample air stream through a laser beam is counted. The device can be runs on direct connection to power. Therefore, four battery banks were purchased so the device could be placed where there was no power available. [19]

\subsubsection{EasyLog, USB-2}

EasyLog USB-2 is a USB stick with sensors for temperature and relative humidity measurements. This small device is easy to install in every zone in the hall, and 7 of them where used in the field study. The battery life of this instrument is 3 years. The measurement is downloaded from a memory card inside the device through a software. [20]

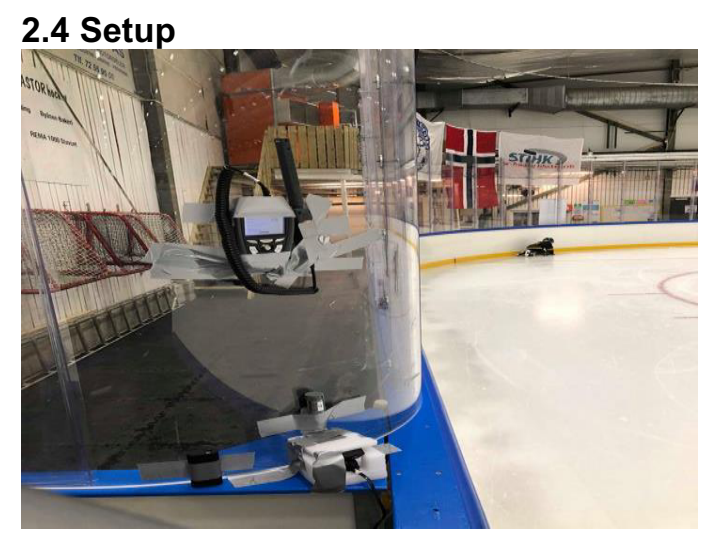

Figure 1. Installation of instruments by the ice rink. 


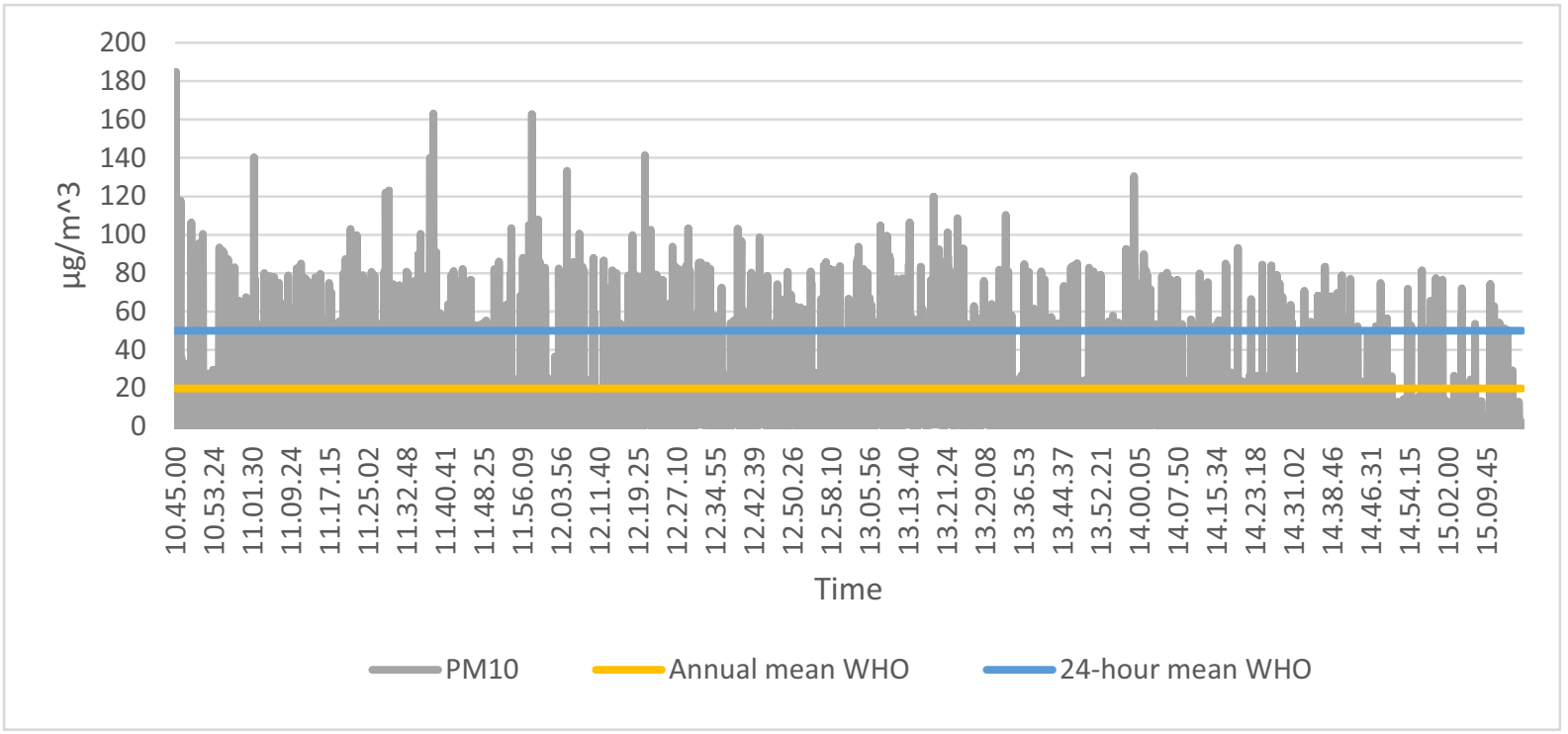

Figure 2. $\mathrm{PM}_{10}$ values by the ice rink.

Three zones in the hall and one in the wardrobe was measured. All the measurement was conducted for one Saturday, 3. November 2018. The reason for choosing this day was due to the different activity levels and different numbers of people present on the rink, the wardrobe and the tribune. Mainly the measurement was conducted between 10:00 and $15: 15$. The open training started around 10:15, so the first measurement was conducted while there were few people inside the hall. This was important in order to see the development of the $\mathrm{CO}_{2}$ concentration and PM in the air with increasing numbers of occupant on the rink.

\section{Results and discussion}

\subsection{Particular matter concentration}

The $\mathrm{PM}_{10}$ level is according to Figure 2, stabile about $80 \mu \mathrm{g} / \mathrm{m}^{3}$ but have the tendency to fall during the day. WHO and Norwegian Institute of Public Health recommend annual mean values of $20 \mu \mathrm{g} / \mathrm{m}^{3}$ and 24 hour mean values of $50 \mu \mathrm{g} / \mathrm{m}^{3}$ and $30 \mu \mathrm{g} / \mathrm{m}^{3}$, respectively. Comparing these values with the measured values, gives reason for concern about the $\mathrm{PM}$ concentration in the air. To high values of $\mathrm{PM}_{10}$, can cause health issues over time. Since many of the young children exercise at Dalgård two or three times a week, it is preferable to lower these $\mathrm{PM}_{10}$ values to ensure an acceptable air quality on the rink. The reason why the $\mathrm{PM}_{10}$ concentration is so high may be that there is no ventilation system that supplies fresh air and exhausts old air. Thus, there is no transporting the particles out of the hall. In a ventilation system it is often a filter that filters out the PM. If there is no such ventilation system, all amounts of PM are likely to increase over time since they have no way to go.

$\mathrm{PM}_{2,5}$ and $\mathrm{PM}_{1}$ values were stable and low by the ice rink, under the recommended values from both institutions mentioned.

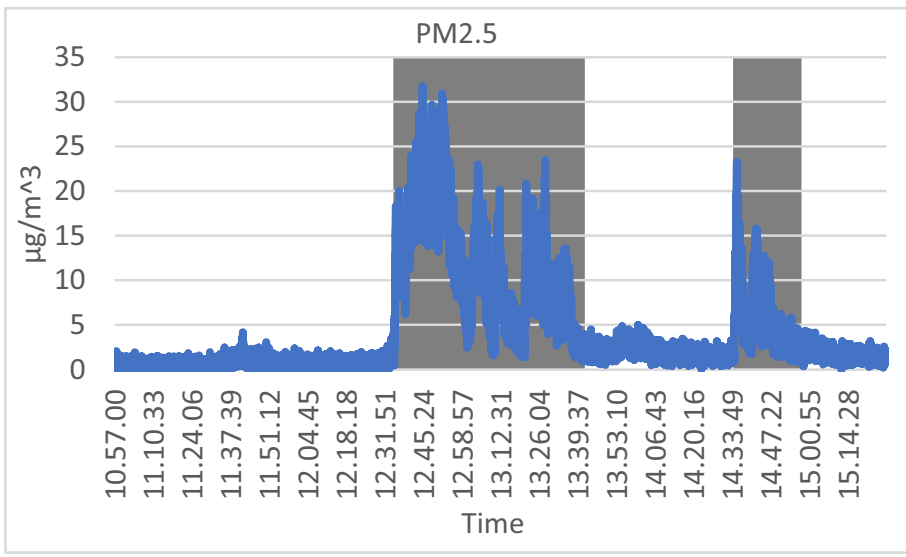

Figure 3. $\mathrm{PM}_{2,5}$ values in the sharpening room.

As Figure 3 shows, it is clear when the sharpening starts and ends. The grey parts represent when the room is in use. $\mathrm{PM}_{2,5}$ values are up to $30 \mu \mathrm{g} / \mathrm{m}^{3}$, but this is just under a shorter period. Skates contains metal and minerals that can be health damaging to the respiratory functions for humans. An air cleaner or filter in ventilation system could maybe not remove the PM fast enough when sharpening. So, perhaps the best way of avoiding this PM exposure could be to use masks. Anyhow, the PM values is decreased to a low level after the sharpening. People do not stay in the room for a long period of time, so the total PM exposure is relatively low. If a person is sharpening skates over a longer period, masks is preferable to avoid too much exposure. The exhaust fan should nevertheless be fixed so the concentration becomes lower after the sharpening. 


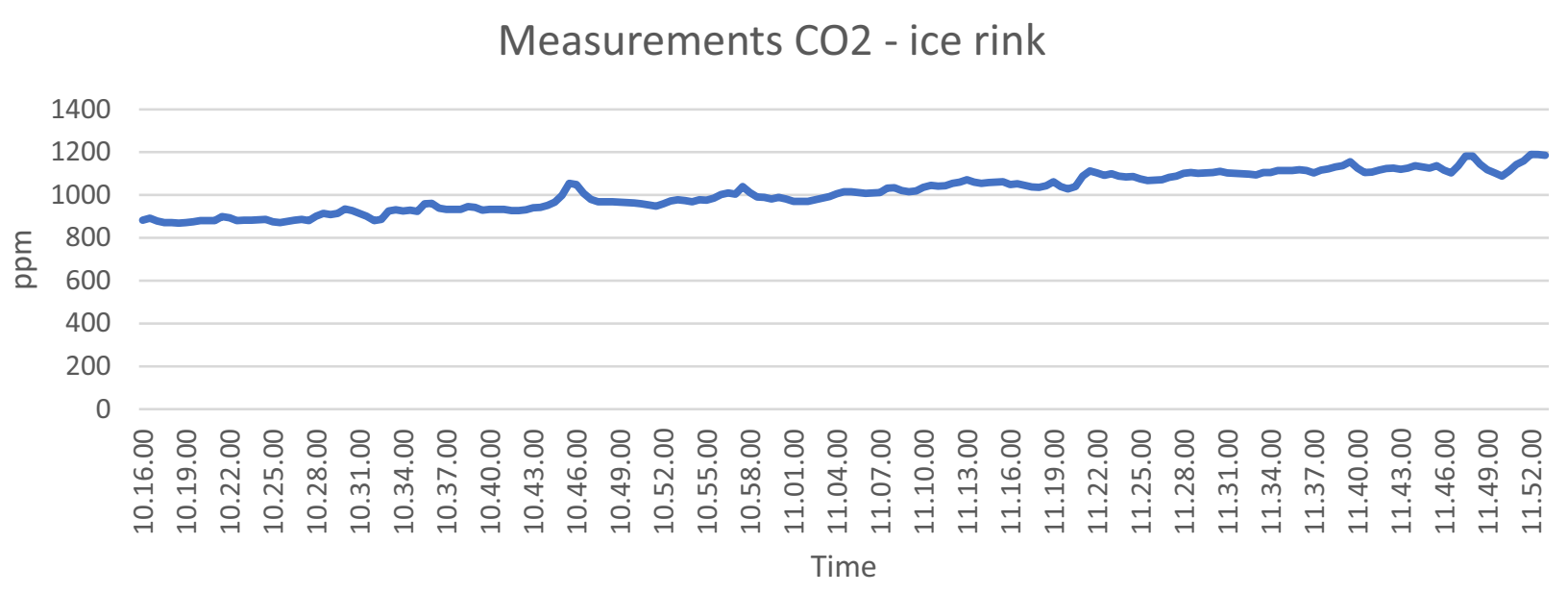

Figure 4. $\mathrm{CO}_{2}$ concentration by the ice rink during training sessions.

\section{$4.2 \mathrm{CO}_{2}$ by the ice rink}

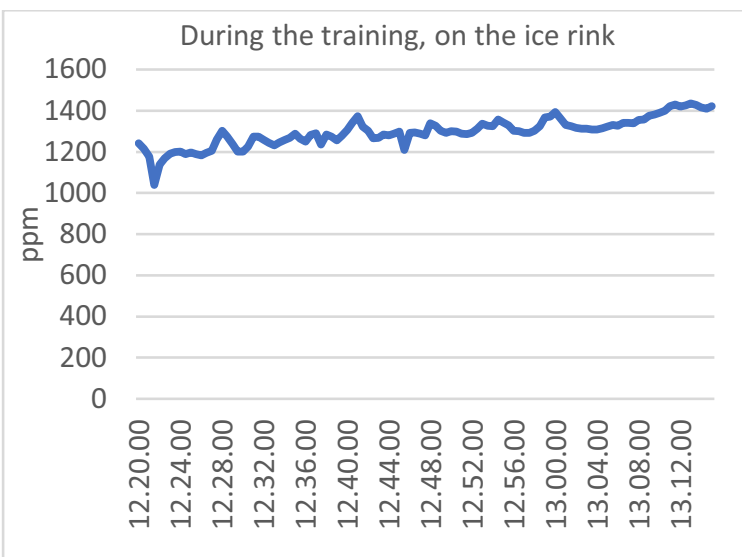

Figure 5. $\mathrm{CO}_{2}$ concentration on the ice rink. A backpack with the instrument is used by one person participating in the training to get closer to the occupied zone.

One can see in Figure 4 and Figure 5 that the concentration increases steadily throughout the day. At first the $\mathrm{CO}_{2}$ level was around $890 \mathrm{ppm}$ before the open training, at the end of the measurement it is about $1400 \mathrm{ppm}$, when the children ended their training. It is worth mentioning that the concentration never decreases significantly, although there where no one on the ice when the resurfacer was preparing the ice.

Norwegian Institute of Public Health recommend a maximum concentration of $1000 \mathrm{ppm}$, which is below the concentration after 3 hours of training. This indicates that the air quality is not good enough.

The only way to lower the $\mathrm{CO}_{2}$ values is by changing the old air with fresh air. Some fresh air comes through leaks in the building envelope and by opening of doors, but the results from these measurements have stated that more fresh air supply is necessary to ensure an acceptable concentration of $\mathrm{CO}_{2}$.

\subsection{Suggested improvements}

Dalgård has no controlled fresh air supply, and it therefore likely to have problems distributing fresh air to the zones of activity. Although open doors and infiltration helps distributing fresh air in to the hall, it is not enough to ensure a good air quality and to supply the amount of fresh air recommended in IIHS's Ice Rink Guide, with 12 1/s per player and 8$10 \mathrm{l} / \mathrm{s}$ per spectator. The most relevant solution is to install a fully mechanical ventilation system, as recommended from IIHF, with ducts and air handling unit including filters for capturing the $\mathrm{PM}_{10}$. This would increase the supply air rate and contribute to keeping the $\mathrm{CO}_{2}$ concentration, and perhaps PM concentration, at a satisfactory low level.

\section{Conclusion}

The literature study in this project found that there are some challenges regarding air quality in large sport facilities. Ice halls are the most investigated facilities due to the challenges of combustion engines in resurfacers, and the challenge due to ventilation, temperature and humidity. Also, a set of studies concluded that high amounts of $\mathrm{PM}$ and $\mathrm{CO}_{2}$ concentration can be linked to health issues and especially affect the respiratory functions. Some studies also show that relatively high $\mathrm{CO}_{2}$ concentrations are related to cognitive functions and productivity on a work place. This can be linked to athletes as they have high pulse and high pulmonary ventilation.

Both $\mathrm{CO}_{2}, \mathrm{PM}$, temperature and relative humidity were measured during one Saturday in November with normal high activity. The $\mathrm{PM}_{10}$ values on the ice rink were quite high and stabile around $80 \mu \mathrm{g} / \mathrm{m}^{3}$. One interesting finding showed 
that the PM values were not affected by the electrical resurfacer. Earlier studies have seen a correlation between combustion engines and fine particles, but the electrical driven resurfacers seems to eliminate that problem. Since no ventilation system transports old air out of the building, it is likely that the PM accumulates over time. A solution to this problem could be to install a free-standing air cleaner with a filter and fan, or by installing a mechanical ventilation system including fine filters.

The $\mathrm{CO}_{2}$ concentration increased steadily on the ice rink during the measurements. It increased from $882 \mathrm{ppm}$ to $1427 \mathrm{ppm}$ during 3 hours of activity. This indicated that the fresh air supply was too low to get rid of the pollutants.

If the results from the studies that shows the correlation between cognitive functions and $\mathrm{CO}_{2}$ level is correct, the performance of the players may be affected by the air quality in Dalgård.

A ventilation system is preferable to ensure a lower concentration of $\mathrm{CO}_{2}$. A solution with mixing ventilation, including fresh and re-circulated air supply through ducts in the ceiling is considered the most current and cost-effective solution. But starting with fixing the exhaust fans and duct seems like a good idea to increase fresh air through infiltration.

More stringent air quality requirements in such big sport facilities should be implemented, as many of these halls does not have a mechanical ventilation system. Young people spend a lot of time in these halls with a high pulmonary ventilation, thus it is important the air quality is good enough to avoid health issues and poorer performance in the sport. A solution could be to implement air quality requirements special for big sport facilities.

\section{References}

1. Folkehelseinstituttet, Anbefalte faglige normer for inneklima, . (2015).

2. NTNU, S., ENØK $i$ bygninger, Effektiv energibruk. (2016). 3rd.

3. IIHF, IIHF ice rink guide, technical report. (2016).

4. Standard Norge, E., EN 15251:2007, Indoor environmental input parameters for design and assessment of energy performance of buildings addressing indoor air quality, thermal environment, lighting and acoustics. (2014).

5. World Health Organization, WHO air quality guidelines for particulate matter, ozone, nitrogen dioxide and sulfur dioxide. (2005).

6. Fanger, P.O., L. Fang, and G. Clausen, Impact of temperature and humidity on the perception of indoor air quality. (1998).

7. Rundell, K.W., High levels of airborne ultrafine and fine particulate matter in indoor ice arenas. (2008).
8. Demokritou, P., et al., The impact of ventilation on air quality in indoor ice skating arenas. (2000)

9. Pennanen, A., Indoor air pollution and health risks in Finnish ice arenas. (2005).

10. Guo, H., S.C. Lee, and L.Y. Chan, Indoor air quality in ice skating rinks in Hong Kong.(2004).

11. K. Meister, C.J., B. Forsberg, Estimated short-term effects of coarse particles on daily mortality in Stockholm, Sweden. (2012). 120(3): p. 431-436.

12. J. B. Byrd, M.M., R. L. Bard, R. Das, L. Wang, Z. Sun, C. Spino, J. Harkema, J. T. Dvonch, S. Rajagopalan, R. D. Brook, Acute increase in blood pressure during inhalation of coarse particulate matter air pollution from an urban location. (2016). 10(2): p. 133-139.

13. D. W. Graff, W.E.C., A. Rappold, H. Zhou, Y.-C.T. Huang, R. B. Devlin, Exposure to concentrated coarse air pollution particles causes mild cardiopulmonary effects in healthy young adults. (2009). 117(7): p. 1089-1094.

14. B. J. Malig, S.G., R. Basu, R. Broadwin, Coarse particles and respiratory emergency department visits in California. (2013). 178(1): p. 58-69.

15. Seppänen, O.A., Association of ventilation rates and $\mathrm{CO} 2$ concentrations with health and other responses in commercial and institutional buildings.. (1999). 9(4): p. 226-252.

16. Allen, J.G., et al., Associations of cognitive function scores with carbon dioxide, ventilation, and volatile organic compound exposures in office workers: A controlled exposure study of green and conventional office environments. Environmental health perspectives, (2016). 124(6): p. 805-812.

17. Satish, U., et al., Is CO2 an Indoor Pollutant? Direct Effects of Low-toModerate CO2 Concentrations on Human Decision-Making Performance. (2012): p. 1671-1677.

18. actoolsupply.com, Kimo AQ 200 Indoor Air Quality Meter.

19. Alphasense, Alphasense User Manual OPC-N2 Optical particle Counter. (2015).

20. Electronics, L., EL-USB-2, Temperature, Humidity and Dew Point Data Logger. (2016). 